Rabaska

Revue d'ethnologie de l'Amérique française

MICHELIN, YVETTE. Fléché traditionnel et actuel. L'art du fléché québécois de la ceinture à la parure. [Préface de CYRIL SIMARD]. Québec, Éditions Les Flécherands du Saint-Laurent, 2015, 88 p. ISBN 978-29815209-0-6

\title{
Anne-Marie Poulin
}

Volume 14, 2016

URI : https://id.erudit.org/iderudit/1037479ar

DOI : https://doi.org/10.7202/1037479ar

Aller au sommaire du numéro

Éditeur(s)

Société québécoise d'ethnologie

ISSN

1703-7433 (imprimé)

1916-7350 (numérique)

Découvrir la revue

Citer ce compte rendu

Poulin, A.-M. (2016). Compte rendu de [MICHELIN, YVETTE. Fléché traditionnel et actuel. L'art du fléché québécois de la ceinture à la parure. [Préface de CYRIL SIMARD]. Québec, Éditions Les Flécherands du Saint-Laurent, 2015, 88 p.

ISBN 978-29815209-0-6]. Rabaska, 14, 259-260.

https://doi.org/10.7202/1037479ar d'utilisation que vous pouvez consulter en ligne. 
Michelin, Yvette. Fléché traditionnel et actuel. L'art du fléché québécois de la ceinture à la parure. [Préface de CYRIL SIMARD]. Québec, Éditions Les Flécherands du Saint-Laurent, 2015, 88 p. ISBN 978-29815209-0-6.

Cette publication, très attendue, est fort bien réussie ! Lancée peu avant la désignation officielle du fléché comme élément unique du patrimoine immatériel du Québec (12 février 2016), elle s'inscrit en continuité de nombreux articles et de plus d'une vingtaine d'ouvrages dédiés au fléché depuis plus d'un siècle. Outre la thèse de doctorat de Monique LeBlanc (1996), le fléché a retenu l'attention de journalistes, de chercheurs et de praticiens tels Pierre Poulin (1896), Édouard-Zotique Massicotte (1907, 1924), Marius Barbeau (1938, 1945, 1973), Cécile Barot (c1948), Cyril Simard (1975), Monique Genest-LeBlanc (1974, 1977, 1991, 1996, 2003), Françoise Bourret et Lucie Lavigne (1973), Véronique Levesque-Hamelin (1993), Denise VerdeauHemlin (1990) et Carol James (2008). Tout comme ses prédécesseurs, Yvette Michelin vise à faire valoir et à conserver cette technique unique au monde - celle du fléché québécois - créée au Québec au milieu du XVIII siècle. Puisant à même ces ressources et s'appuyant sur quarante-cinq années d'expérience de tissage, d'enseignement et de production du fléché, l'auteure livre un texte à la fois ethnohistorique, esthétique et didactique tourné résolument vers le XXI ${ }^{\mathrm{e}}$ siècle.

L'œuvre de 88 pages, qui a été réalisée à compte d'auteur, affiche une facture soignée sur papier et couverture glacés, avec graphisme professionnel à l'avenant, des illustrations et photographies couleur, une qualité d'impression «Offset » et, fait rarissime, une reliure cousue et collée. Présentée en format magazine, telle une revue d'art et d'artisanat, la publication comprend deux parties. Celles-ci sont précédées d'une préface de Cyril Simard, présidentfondateur du réseau Économusée, d'un résumé historique, d'une définition du fléché, montrant l'évolution même récente de la technique, et enfin des précisions pour bien distinguer le fléché québécois du chevron universel. Ces deux tissages aux doigts ayant une forte ressemblance sur le plan visuel peuvent en effet porter à confusion.

La première partie fait la part belle, comme il se doit, à la réalisation du fléché québécois. Près de soixante pages y sont consacrées. S'y trouvent, en premier lieu, les notions de base et les consignes qui sont détaillées et accompagnées d'illustrations, de graphiques et de photos pertinentes. Par la suite, on y présente le mode de tissage d'une quinzaine de motifs traditionnels et actuels, dont certaines créations par l'auteure et d'autres par des confrères ou des consœurs flécherands. Une dernière section indique la pagination de capsules d'informations diverses que l'on retrouve intercalées ici et là à travers tout le texte. C'est dans ces « encadrés », que l'on fait l'histoire du mot « flécherand » créé par l'auteure et officiellement reconnu par l'Office 
québécois de la langue française (p. 65), qu'est racontée celle des galons et des jarretières de la Nouvelle-France (p. 73) et que l'on évoque la symbolique de la flèche (p. 56). Toutefois, pour quiconque s'intéresse aux savoirs et aux savoir-faire en art textile et à leur histoire, l'information et le visuel les plus percutants de l'ouvrage figurent aux pages 66 et 67 . C'est ici que l'on perçoit, d'une part, les différences entre le tressage, le fléché et le chevron universel, et la nette distinction, d'autre part, entre les deux types de tissage aux doigts que sont le fléché et le chevron. Cette démonstration permet, à elle seule, d'éliminer les doutes, le questionnement ou le scepticisme quant à la terminologie et la technique propres au fléché québécois. Bref, de reconnaître facilement son caractère unique et original.

La deuxième partie du manuel comprend une dizaine de pages et vise à initier le lecteur au chevron, technique élémentaire de tissage aux doigts qui a précédé le fléché. L'auteure en propose l'étude et la pratique dans le but de faciliter la compréhension et de saisir la différence entre les deux types de tissage aux doigts. Six motifs de chevron sont proposés en guise de pratique préalable à la réalisation du fléché. Tout comme dans la première partie de l'ouvrage, des encadrés avec trucs, suggestions et capsules guident l'apprenti et renseignent le profane. Un glossaire de trois pages constitue également un outil précieux pour la compréhension de la technique et son vocabulaire.

Outre ces caractéristiques d'ordre technique et pédagogique, l'ouvrage fait une place importante aux porteurs de traditions. L'auteure se montre d'abord très reconnaissante envers ses prédécesseurs, particulièrement ceux et celles, anonymes il faut le dire, qui ont eu le " génie » de créer le fléché québécois et d'en maintenir la pratique. L'esprit d'ouverture est également perceptible tout au long de la présentation. De fait, Yvette Michelin n'hésite pas à mettre plus particulièrement en valeur ces flécherandes qui ont fait évoluer la technique depuis les cinquante dernières années, à illustrer des créations contemporaines et à inviter les adeptes actuels « à en explorer [...] les possibilités infinies » (p. 82). Il en ressort, enfin et surtout, un souci évident de clarté visant à éliminer certaines ambiguiités relatives à la technique et à son histoire, à l'origine de certains motifs ou encore à la sémantique. Un éclairage fort utile tant pour le praticien que l'ethnologue, l'historien et le muséologue. Cette préoccupation, qui est tout à l'honneur de l'auteure, est d'ailleurs palpable dans le contenu des encadrés autant que lorsqu'elle rappelle que « le présent livre ne fait pas office de livre de recettes, mais cherche plutôt à augmenter la compréhension de la technique du fléché dont nous évoquons les bases » (p. 11). Force est d'admettre que le pari est réussi ! 